\title{
Mora y Echeverría: dos visiones sobre la soberanía popular en el siglo XIX
}

\author{
María Ligia Coelbo Prado \\ UNIVERSIDAD DE SÃo PAULO
}

$\mathrm{E}$ 1 periodo posterior a la independencia política en la América española es particularmente interesante para ser estudiado, porque la emergencia de aspiraciones sociales divergentes en esa época de cambios institucionales hizo aparecer en el escenario político un intenso debate entre sujetos política e ideológicamente opuestos. La construcción de los Estados nacionales implicó un largo proceso de luchas sociales y políticas donde, muchas veces, el consenso no llegó sino después de largas guerras civiles en que se confrontaron adversarios poderosos.

Las diferencias entre el pensamiento político conservador y el liberal son viejos temas de la historiografia lati- noamericana. ${ }^{1}$ Mientras que el problema de la democracia fue, por lo general, olvidado, relegado a un segundo plano, $o$ incluso, mal interpretado. Una confusión común es creer que liberalismo y democracia son conceptos idénticos, y tomar a un político liberal -como han hecho rantos historiadores con Bolívar- por un demócrata. ${ }^{2}$

1 Véanse los interesantes textos organizados por Romero, Conservador, 1978 y Pensamiento, 1977, especialmente el prólogo.

2 Sobre el liberalismo, véase Vachet, Ideologia, 1972, y Dumont, Essays, 1986. Sobre democracia, véase McPherson, Democracta, 1978, y Sartori, Theory, 1987. Para una discusión actual sobre el tema de la democracia en América Latina, véase Fundación Pablo Iglesias, Caminos, 1984. 
No es preciso reafirmar que la construcción de la democracia en América Latina ha sido extremadamente difícil y que la conquista de la ciudadanía de las clases populares es todavía, en algunos países, una meta por alcanzar. Algunos estudiosos procuraron dar a este problema interpretaciones genéricas que veían, por ejemplo, en la herencia colonial iberoamericana o en la dependencia estructural con respecto al mercado internacional, la explicación central de la permanencia del autoritarismo y de la dictadura en el continente.

Creo que necesitamos hacer investigaciones históricas que estudien las especificidades de las relaciones entre dominantes y dominados comenzando por el periodo de la formación de los Estados nacionales, analizando, por una parte, la naturaleza de las aspiraciones democráticas de los dominados y, por la otra, las distintas respuestas de los sectores dirigentes, ante situaciones sociales y políticas diversas. Mi modesta contribución a este tema es la de analizar las justificaciones presentadas por dos liberales latinoamericanos, en sus escritos de 1820 a 1830 , en el sentido de limitar el concepto de soberanía popular a ciertos sectores privilegiados de la sociedad.

Los dos autores escogidos -el argentino Esteban Echeverría y el mexicano José María Luis Mora- son considerados como defensores de los principios liberales, en oposición a las ideas conservadoras de su tiempo. Ellos estaban preocupados con semejantes cuestiones sociales y políticas, y tocaron temas bastante próximos.

Esteban Echeverría (1805-1851), aunque mejor conocido como poeta y escritor, formaba parte de un grupo de intelectuales y políticos -entre ellos Juan Bautista Alberdi y Juan María Gutiérrez- llamado la Generación del 37 , que se opuso activamente al federalista Juan Manuel de Rosas, gobernador de la provincia de Buenos Aires desde $1829 .{ }^{3}$ El joven Echeverría, después de visitar Francia en el agitado periodo de Luis Felipe de Orleáns, volvió a su país firmemente dispuesto a proponer cambios para Argentina.

En ese periodo, Argentina, después de una efimera experiencia en que el país estuvo unificado bajo un gobierno centralizado, constituía una frágil federación de provincias, dominada por el gobernador de Buenos Aires. ${ }^{4}$ Éste, particularmente después de la muerte de su rival político más poderoso, Facundo Quiroga, en 1835, extendería su poder político por todo el país mediante una serie de pactos arbitrados entre los demás gobernadores. En Buenos Aires, contaba con el apoyo político de los grandes hacendados, y procuró responder a sus demandas con medidas que intentaban, por una parte, legalizar la propiedad de la tierra y, por la otra, organizar el incipiente mercado de trabajo, colocando la mano de obra dentro de un esquema típicamente capitalista. Dio especial atención al problema de la fron-

3 Los libros más conocidos de Echeverría son: La cautiva (poesía) y El matadero (novela); Domingo Fáustino Sarmiento se consideraba catecúmeno de la Generación del 37.

4 Sobre la Argentina rosista, véanse, entre otros: Gorostegui de Torres, Organizacion, 1972; Lynch, Argentine, 1981; Hal perin Donghi, Revolución, 1972; Ozlak, Formación, 1982. 
tera, expandiéndose en dirección al sur, por medio de campañas militares contra los indios. Aunque representaba los intereses de los hacendados (siendo él mismo uno de ellos), desarrolló una política de cooptación de los grupos populares, que le respondieron con apoyo estusiasta, especialmente en Buenos Aires. ${ }^{5}$

Gobernó Buenos Aires con plenos poderes y persiguió a sus enemigos políticos, de manera particular a los unitarios, con implacable deter. minación. Para éstos, Rosas representaba la encarnación del absolutismo, de la arbitrariedad y de la barbarie, todo lo contrario de los principios liberales que ellos defendían. Un grupo que se sentía responsable de la "sagrada misión" de definir a la nación argentina fundó en Buenos Aires, el 8 de julio de 1838, una asociación secreta, denominada Joven Argentina, a semejanza de sus congéneres europeas, Joven Italia, Joven Polonia, etc. Proponían la formación de un Estado guiado por los principios liberales y por las luces de la razón, que forjarían una constitución obedecida y respetada para poner fin, mediante la conciliación, a las luchas que dividían a Argentina. Echeverría era uno de sus lideres.

La represión política por parte del régimen rosista obligó a sus opositores, para escapar de la prisión e incluso de la muerte, a buscar el exilio en Chile o en Uruguay, a fin de mantener viva, a través de sus escritos, la resistencia política contra el gobernador. Echeverría partió a Montevideo, y

\footnotetext{
5 Véase el arrículo de Ansaldi, "Forja", 1981.
}

el manifiesto de la Asociación Joven Argentina, que él habia escrito, fue publicado allá, por primera vez, en el periódico El Iniciador, el 1 de febrero de 1839, adoptando posteriormente el título definitivo de Dogma Socialista de la Asociación de Mayo. ${ }^{6}$

El Dogma, compuesto de varios tópicos, es una síntesis de los principios políticos defendidos por Echeverría y se inicia con la enumeración de las palabras simbólicas de lo que él llamaba la "Fe de la joven generación argentina: asociación, progreso, fraternidad, igualdad, libertad, Dios, democracia". En el ítem 12, "Organización de la patria sobre una base democrática", el autor presentaba su concepto de democracia. Afirmaba Echeverría: "La democracia parte de un hecho necesario, es decir, la igualdad de las clases, y marcha con paso firme en dirección a la conquista del reino de la libertad más amplia, de la libertad individual, civil y política."7 La democracia, continuaba, es el gobierno de las mayorías o el consentimiento de la razón de todos; ese consentimiento general es la soberanía del pueblo. La soberanía del pueblo es ili-

6 Estoy utilizando la edición organizada por Carlos M. Rama, Utopismo, 1977, que contiene varios textos más (Flora Tristán, Francisco Bilbao, etc.). Es necesario afirmar que el texto de Echeverría estaría mejor en una selección de textos liberales, porque de socialista conserva apenas el título. Según José Luis Romero, el manifiesto tuvo al principio el tútulo de Creencta o Credo, y fue revisado por Echeverría y Alberdi, pero en 1864, Echeverría lo retomó con el título por el cual fue conocido. Romero, Ideas, 1981, p. 139.

7 Cfr: Echeverría, Dogma, 1977, p. 118. 


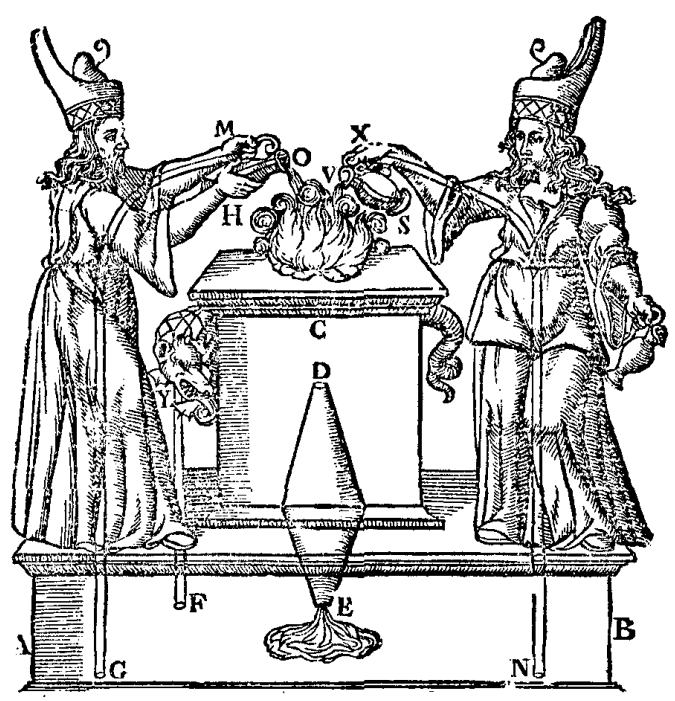

mitada en lo que se refiere a la sociedad, pero no en lo que toca al individuo, su conciencia, sus propiedades, su vida, su libertad. La democracia debe asegurar a todos y a cada uno el más amplio y libre disfrute de sus derechos naturales y, así, el pueblo soberano o la mayoría no puede violar los derechos individuales que son el origen de la asociación. El límite de la razón colectiva es el derecho y el límite de la razón individual es la soberanía de la razón del pueblo. De ahí resulta su primer principio: "Ia soberanía del pueblo es ilimitada en cuanto respeta el derecho del individuo."B

A la primera oposición entre los derechos del individuo y los derechos colectivos, sigue una segunda que es la

8 Ibid., p. 120. oposición entre razón colectiva y voluntad colectiva. Afirmaba Echeverría que la razón examina, pesa, decide, mientras que la voluntad es ciega, caprichosa, irracional. Por lo tanto, la soberanía del pueblo sólo puede residir en la razón del pueblo, siendo llamada a ejercer la soberanía sólo la parte sensata y racional de la comunidad social. La democracia no es, de esta manera, el despotismo de las masas ni de las mayorías, sino el régimen de la razón. Los ignorantes que no pueden distinguir el bien del mal, deben some. terse a los que tienen el dominio de las luces; y los vagabundos y aquellos que no tienen oficio no pueden formar parte de la soberanía del pueblo, porque no tienen ningún interés que los ligue a la sociedad y necesitan, por lo tanto, de una tutela. (Consecuente- 
mente, razón y trabajo están intrínsecamente vinculados a la soberanía del pueblo.) Su segundo principio dice: "La soberanía del pueblo es absoluta en cuanto que tiene por norma a la razón." 9

Las masas ignorantes, aunque privadas del ejercicio de los derechos de su soberania o de su libertad política, están en pleno gozo de la libertad individual. Según Echeverría, las masas tienden al despotismo, están guiadas por los instintos y son sensibles al im. perio de la voluntad y no al de la razón.

Finalmente, el tercer principio anuncia que cuando todos los miembros de la asociación tengan plena posesión de las libertades -la individual, la civil y la política- y las ejerzan, quedará plenamente constituida la democracia. ${ }^{10}$ Mas, para alcanzar tal estado, es preciso preparar a las masas para el desempeño de las actividades políticas a través de la educación, que les será administrada por aquellos que detentan las luces. (Así se cierra el círculo de los elegidos para el ejercicio de la democracia y de aquellos que deben permanecer afuera, esperando el ronsentimiento de los ilustrados.)

Los escritos políticos de Echeverría, aunque influenciados por las lecturas de Saint Simon, Fourier y Lamennais, entre otros, emergen de los dramas sociales de la Argentina en aquel periodo. Rosas, "el bárbaro", "el déspota", contaba con apoyo popular, repetidamente reiterado en momentos de crisis. Las "masas" que lo respaldaban eran consecuentemente peli-

9 Loc. cit.

10 Loc, cit. grosas, se dejaban llevar por los instintos y por la voluntad engañadora. Los civilizados, guiados por las luces de la razón, capaces de distinguir el bien del mal, constituían el único grupo apto para ejercer el poder, después de la caida del "dictador" Rosas. Para llevar a la Argentina por el camino del progreso, era necesario encontrar los medios legales que impidiesen la participación política de los impreparados.

Echeverría no vivió para ver la victoria de los liberales, después de la caída de Rosas en 1852, pero algunas de sus ideas pasaron a ser políticamente dominantes. Sin duda, otros liberales, que compartían los mismos principios, tales como Juan Bautista Alberdi y Domingo Faustino Sarmiento, contribuyeron e influenciaron más poderosamente los debates políticos de aquel periodo. Alberdi escribió un texto que establece una base fundamental de la Constitución de 1853 (en que el presidente de la república no era electo por sufragio universal) y Sarmiento, además de tener una producción de libros importantes, llegó a la presidencia de la Argentina en $1868 .{ }^{11}$ Mientras, en el Dogma, Echeverría presentaba un análisis sucinto, reflexivo y pormenorizado del concepto de democracia, justificanau con argumentos filosóficos la exclusión de los sectores populares del ejercicio legal de la política.

11 Ia bibliografía argentina sobre Sarmiento y Alberdi es extensísima, cito sólo algunos de los ensayos más recientes: Botana, Tradición, 1984; Altanimo y Sarlo, Ensayos, 1983; Halperin Donghi, Nacion, 1982; Lacay, Samiento, 1986; vease también el trabajo clásico de José Luis Romero, Ideas, 1946. 
No se debe olvidar que en el espectro político de la Argentina de ese periodo, Echeverría debe ser visto como un republicano radical.

José María Luis Mora (1794-1850), a pesar de haber recibido las órdenes sacerdotales, se inscribió en el debate político del México indepediente como uno de los principales defensores de los principios liberales. Asumió una perspectiva ideológica de combate, ${ }^{12}$ en un periodo en que el país estaba dividido entre liberales y conservadores que presentaban proyectos políticos divergentes para la construcción del Estado nacional. Como en ningún otro país de América Latina, la lucha por los bienes de la Iglesia dividió tan profundamente a la sociedad y desencadenó una guerra civil de proporciones tan agudas. A grosso modo, los liberales exigían la extinción de los fueros especiales eclesiásticos y la nacionalización de sus bienes, mientras que los conservadores defendían los privilegios de la Iglesia, así como los del ejército y soñaban con una monarquía que fuese capaz de poner orden en lo que ellos veían como caos político. Fue una larga $e$ instransigente lucha que terminó con la victoria de los liberales y la subordinación de la Iglesia al Estado laico, en la segunda mitad del siglo XIX. ${ }^{13}$

12 Expresión utilizada por Zea, Positivismo, 1971. Sobre el pensamiento de Mora: Hale, Mexican, 1968. Sobre el liberalismo en México, véase el clásico de Reyes Heroles, Liberalismo, 1957-1961; Villoro, Proceso, 1984; Miranda, "Liberalismo", 1959; Knight, "Liberalismo", 1985.

13 Hay también una amplia bibliografía sobre
Mora tuvo una actividad política $e$ intelectual intensa: pertenecía a la masonería, fue electo diputado más de una vez para la legislatura del estado de México y expuso sus ideas en varios periódicos políticos que fundó y dirigió. Deciaró que discrepaba del partido que representaba a "su clase" (el clero) y que renunciaba a "todos los privilegios civiles" de la misma, porque su posición política lo colocaba contra todo tipo de privilegios. El combate que Mora emprendió era en contra de los privilegios coloniales, concentrados fundamentalmente en la Iglesia y el ejército, a los que él veía como las fuerzas del retroceso. El Partido del Progreso, que él defendía, proponía la desamortización de los bienes de la Iglesia, la abolición de los privilegios del clero y del ejército, la difusión de la educación pública, la libertad de opinión, la igualdad para los extranjeros y el establecimiento de un tribunal de jure. ${ }^{14}$

Mora escribió sobre problemas políticos contemporáneos, pero hizo también incursiones en la historia, habiendo proyectado escribir una historia de México desde la independencia, en ocho yolúmenes, de los cuales sólo terminó tres. Como Echeverría, reflexionó sobre el significado de las libertades y de la soberanía popular, determinando quién estaba (y quién no estaba) preparado para usufructuar el derecho de hacerse representar políticamente. Distinguía ep la his-

esos temas, cito solo algunos de los trabajos ya clásicos, que son sólidos análisis del periodo: Bazant, Bienes, 1971; Cosío Villegas, Historia, 1955; López Cámara, Estructura, 1967.

${ }^{14}$ Hale, Mexican, 1968, p. 115. 
toria de las naciones tres grados de civilización: un estado de infancia en que los hombres sólo podían, bajo la tutela de sus jefes, gozar de la libertad civil; en una segunda etapa, con el "desarrollo de las facultades humanas", los hombres pasarían a tener libertad administrativa, para encargarse de dirigir los asuntos locales; finalmente, después de los "avances de la civilización y del progreso", se llegaría a una época en que las naciones estarían listas para adquirir las libertades políticas. Para Mora, México estaba entrando en la tercera fase $y$, por ello, se necesitaba mucha cautela en la cuestión de los derechos políticos, para que fuesen evitados futuros problemas debidos a la precipitación. ${ }^{15}$
Algunos de los mayores males de la república -caos político, desorden social, luchas intestinas- habian sido causados, según él, por la "peligrosa y funesta palabra igualdad". Los excesos de la teoría igualitaria de democracia política, podían ser medidos por la "escandalosa profusión con que se prodigaron derechos políticos, haciéndolos extensivos y comunes hasta las últimas clases de la sociedad". ${ }^{16}$ En nombre de la igualdad, un puñado de hombres "sin educación y sin principios" ocuparon puestos públicos, conduciendo la ad. ministración pública al desastre.

Las "pasiones populares" habían transformado la Cámara de Diputados en algo semejante a la Convención

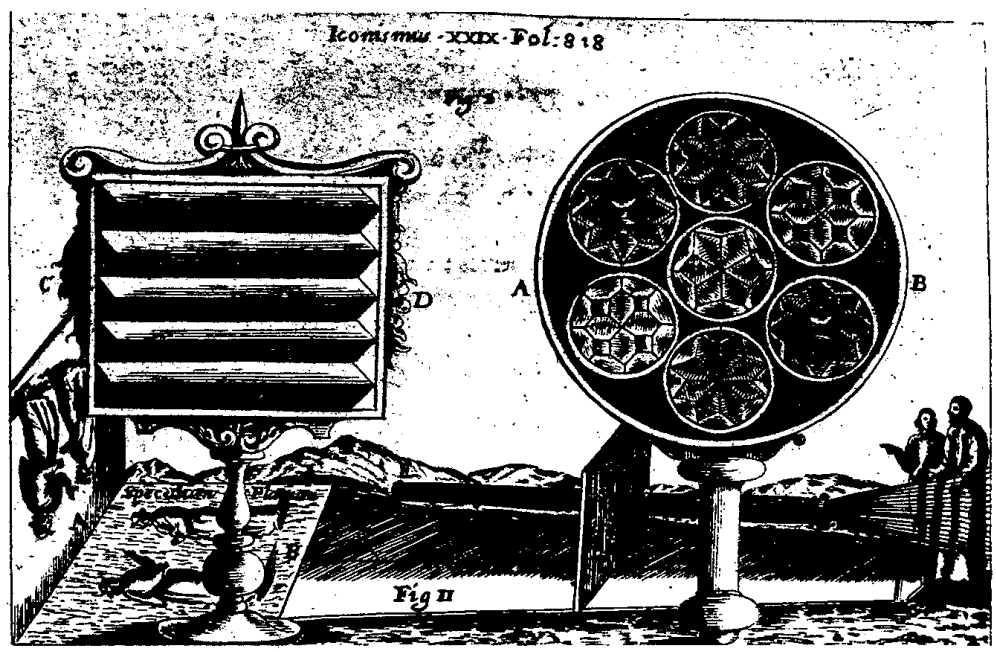


francesa, en el periodo revolucionario, porque ya no era un "instrumento activo" gobernado por la "razón de los representantes", sino un "cuerpo pasivo", sujeto a la "voluntad de un número de facciosos, charlatanes y atrevidos". La calma y la deliberación racionales había dejado su lugar a la pasión y, más de una vez, los derechos individuales se habían reducido en nombre de la voluntad general. ${ }^{17}$ En su Catecismo político de la federación mexicana, de 1831, escrito en forma de preguntas y respuestas, atacaba el concepto de soberanía popular y voluntad general, proponiendo la acción de una "autoridad competente", que fuese capaz de controlar la "voluntad general". ${ }^{18}$

Para evitar todos esos males, Mora recomendaba la limitación de la par. ticipación política popular y determinaba que el Congreso fijase "las condiciones para ejercer el derecho de ciudadanía en toda la república y que por ello quedasen excluidos de su ejercicio todos los que no pudiesen inspirar confianza alguna, esto es, los no propietarios". ${ }^{19}$ Por lo tanto, para él, razón y propiedad estaban ligadas, en el momento de decidir cuál era la parte de la sociedad que tenía responsabilidades para con el bien común y que estaba preparada para ejercer los derechos políticos. Es conveniente recordar que incluso un liberal radical como Lorenzo de Zavala, que había defendido los principios democráticos en 1828 , tres años más tarde abogaría

17 Hale, Mexican, 1968, p. 103.

18 Hale, Mexican, 1968, pp. 107-108.

19 Mora, Obras, 1963, p. 631. por la limitación del voto exclusivamente a los propietarios como un medio de evitar la demagogia y la intriga política. ${ }^{20}$

Mora, un republicano convencido, a semejanza de Echeverría, trabajaba con conceptos pensados en Europa -la influencia de Benjamín Constant sobre sus escritos es notable-, pero su reflexión política partía de la situación histórica mexicana y de los conflictos y luchas sociales de su país. Lo apoyó y fue una especie de consejero del gobierno liberal de Valentín Gómez Farías, en 1833; con el derrocamiento del gobierno por los conservadores, partió al año siguiente a Europa, donde pasó los últimos catorce años de su vida. Creo que además de las situaciones políticas en que se vio inmerso, la rebelión campesina que impulsó las luchas por la independencia, ejerció sobre Mora un fuerte impacto. Consideraba a Hidalgo un líder irresponsable que actuaba sin medir las consecuencias de sus actos y que permitía que las "masas ignorantes" participasen en el ejército en pie de igualdad con las fuerzas militares, entrenadas y organizadas. Mora lo veía como un demagogo a quien los campesinos seguían simplemente por ignorancia y falta de discernimiento. El primer capítulo del tercer tomo de su libro sobre la independencia mexicana, México y sus revoluciones, empezaba con una frase reveladora de su perspectiva: "La revolución que irrumpió en septiembre de $\mathbf{1 8 1 0}$ fue tan necesaria para la consecución

20 Hale, Mexican, 1968, p. 96. 
de la independencia, como perniciosa y destructiva para el país."21

Para prevenir el peligro de una nueva rebelión campesina, era necesario que el poder político estuviese en manos de aquellos que poseyeran cualidades adecuadas para mantener el orden y también sensibilidad suficiente para precaverse de las "revolu. ciones de los hombres", prescribiendo las "revoluciones del tiempo". Por lo tanto, era preciso que la soberanía popular y la participación democrática fuesen postergadas para su "debido tiempo", por la prudencia y perspicacia de los gobernantes. ${ }^{22}$ El pueblo debía aguardar y tener paciencia, hasta que, a través de la educación, estuviese preparado para ejercer las libertades políticas.

Recordando a Zavala una vez más, él afirmaba, en 1833, que en México no había y no habría democracia, porque la "impreparación" de la población era enorme; por ejemplo, de los 200000 votantes del Estado de México, dos tercios eran analfabetos, la mitad no tenía con qué vestir, un tercio no sabía español y tres quintos eran instrumentos del partido que estaba en el poder. ${ }^{23}$ Se sobrentendía, en esa declaración, que los indios no tenían capacidad para desempeñar ninguna actividad política y que el "pueblo" en general no sabía escoger de manera correcta en el momento de votar. Ninguno de esos ideólogos y políticos juzgaba posible la idea de que los indios, los mestizos o los blancos pobres pu-

21 Mora, México, 1950, vol.nI, p. 15.

22 Mora, Obras, 1963, p. 749.

23 Hale, Mexican, 1968, p. 123. diesen aprender por sí mismos las reglas del juego democrático y decidir quién era mejor para que los representase políticamente.

La defensa de la limitación de los derechos políticos pasa por una perspectiva ilustrada y elitista propia de los liberales del siglo XIX, tanto en América Latina como en Europa. No quiero establecer ningún tipo de generalización abstracta, sino apenas recordar que en Europa, en esa misma época, había un intenso debate sobre la cuestión de la soberanía popular en el campo ideológico liberal, con la proposición de una serie de mecanismos legales para evitar la "peligrosa" participación política popular. Esos límites sólo pudieron ser superados por la efectiva lucha de los grupos discriminados para alcanzar la ciudadanía.

¿Quiénes eran los destinatarios de los textos de Mora y Echeverría? Para este último, "la parte sensata y racional de la comunidad social", y, para Mora, los hombres propietarios que se destacaban por "su virtud, su talento, sus luces y su valor". Ambos eran liberales que tenían propuestas políticas para la conformación de los Estados nacientes y que pretendían traducir los intereses de aquellos a los cuales dirigían sus escritos. Se estaban oponiendo, a través de argumentos racionales, a sus enemigos políticos, poderosos dentro de los sectores dominantes; en Argentina, a los federalistas rosistas y, en México, a los conservadores ligados a la Iglesia y al ejército. No se dirigían a los sectores populares, porque éstos no eran considerados como interlocutores políticos, pero aun así, los dominados estaban presentes en sus dis- 
cursos como amenaza, como peligro y, por eso mismo, habían sido descalificados como sujetos políticos, acusa. dos de ignorancia, impreparación, inmadurez o irracionalidad. Las tensiones sociales y los antagonismos políticos eran el punto de partida y el punto de llegada de esos discursos.

El texto de Echeverría como los escritos de Mora respondian a cuestiones políticas puestas en boga por la situación histórica de sus países y estaban plenamente adecuados a la "realidad" de América Latina. Por ello discrepo de la lectura y de la construcción de ciertas interpretaciones, que separan o yuxtaponen de un lado, el "pu. rismo" de los presupuestos liberales y democráticos, y de otro, la "cruda y violenta realidad latinoamericana". 24 No hay separación, todos estos elementos están unidos por la dinámica propia de la dominación burguesa y por la dialéctica de las relaciones entre dominantes y dominados.

Las clases populares no pudieron hacer frente a los proyectos antidemocráticos idealizados y llevados a la práctica por los sectores vencedores. No porque aquéllas hubiesen demostrado pasividad o sumisión, sino porque su rebeldía no se canalizó a través de una propuesta alternativa sólida, y porque no tenían fuerza política suficiente para imprimir una dirección distinta a las decisiones dominantes

24 La perspectiva de yuxtaposición está, por ejemplo, en Villegas, Reforma, 1979. En Brasil, hay un extenso debate sobre la cuestion, en, por ejemplo, Carvalho Franco, "Ideas", 1976; Schwarts, "Ideas", 1973; Viotti da Costa, "Liberalism", 1985. que las excluyeron del derecho a la ciudadanía.

En suma, he procurado mostrar que la cuestión de la democracia y del derecho a la ciudadanía sólo puede ser entendida a la luz del análisis de situaciones históricas específicas, con énfasis en el problema de las luchas sociales y de los conflictos políticos que las rodean. Si buscáramos explicaciones a partir de concepciones genéricas, como la dependencia o la herencia colonial, quedaríamos atrapados en un esquema preconstruido, que nos daría a priori las respuestas que investigamos. Creo que es importante observar que las justificaciones elaboradas por esos liberales del siglo XIX, en un momento dado, fueron utilizadas posteriormente, para fundar una perspectiva de "atraso" y de "impreparación" de los sectores liberales para el ejercicio de la democracia, que acabó por transformarse en "verdad" incuestionable, "fruto del pasado histórico de América Latina".

\section{BIBLIOGRAFÍA}

-Altamirano, Carlos y Beatriz Sarlo, Ensayos argentinos. De Sarmiento a la vanguardia, Centro Editor de América Latina, Buenos Aires, 1983.

-Ansaldi, Waldo, "La forja de un dictador. El caso de Juan Manuel de Rosas", Crítica y Utopia, núm. 5, Buenos Aires, 1981.

-Bazant, Jan, Los bienes de la Iglesia en México (1856-1875), El Colegio de México, México, 1971.

-Botana, Natalio R., La tradición republicana. Alberdi, Sarmiento y las ideas politicas de su tiempo, Editorial Sudame. ricana, Buenos Aires, 1984. 
-Carvalho Franco, María Silvina de, "Las ideas están en su lugar", Cuadernos de Debate, núm 1, 1976.

-Cosío Villegas, Daniel, Historia moderna de México, Editorial Hermes, México, 1955-1972, 10 vols.

-Dumont, Louis, Essays on individualism, Chicago University Press, Chicago, 1986.

-Echeverría, "Dogma, socialista de la Asociación de Mayo", en Carlos M. Rama, Utopismo socialista (1830-1893), Biblioteca Ayacucho, Caracas, 1977.

-Fundación Pablo Iglesias, Caminos de la democracia en América Latina, Fundación Pablo Iglesias, Madrid, 1984.

-Gorostegui de Torres, Haydée, La organización nacional, Paidós, Buenos Aires, 1972.

-Hale, Charles, Mexican liberalism in the age of Mora, 1821-1853, Yale University Press, New Haven, 1968.

-Halperin Donghi, Tulio, Revolución y guerra. Formación de una elite divigente en la Argentina criolla, Siglo XXI Editores, Buenos Aires, 1972.

- Una nación para el desierto angentino, Centro Editor de América Latina, Buenos Aires, 1982.

-Knight, Alan, "El liberalismo mexicano desde la reforma hasta la revolución (una intepretación)", Historia Mexicana, vol. XXXV (1), núm. 137, julio-septiembre 1985.

-Lacay, Celina, Sarmiento y la formación de la clase dominante, Editorial Contrapunto, Buenos Aires, 1986.

-López Cámara, Francisco, La estructura económica y social de México en la época de la reforma, Siglo XXI Editores, México, 1967.

-Lynch, John, Angentine dictator: Juan Manuel de Rosas, 1829-1852, Claredon Press, Oxford, 1981.

-McPherson, C. B., A democracia liberal, Zahar, Río de Janeiro, 1978.

-Miranda, José, "El liberalismo mexicano y el liberalismo europeo", Historia
Mexicana, vol. VIII (4), núm. 32, abriljunio, 1959.

-Mora, José María Luis, México y sus revoluctones, Editorial Porrúa, México, 1950, 3 vols.

, Obras Sueltas, Editorial Porrúa, México, 1963.

-Ozlak, Oscar, La formación del Estado argentino, Editorial Belgrano, Buenos Aires, 1982.

- Rama, Carlos M. (comp.), Utopismo socialista (1830-1893), Biblioteca Ayacucho, Caracas, 1977.

-Reyes Heroles, Jesús, El liberalismo mexicano, UNAM, México, 1957-1961, 3 vols.

-Romero, José Luis, Las ideas políticas en Argentina, FCE, Buenos Aires, 1946. (3a ed., Fondo de Cultura Económica, Buenos Aires, 1981.)

-Romero, José Luis y Luis Alberto Romero, Pensamiento político de la emancipación, (1790-1825), Biblioteca Ayacucho, Caracas, 1977, 2 vols.

, Pensamiento conservador; (1815-1889), Biblioteca Ayacucho, Caracas, 1978.

-Sartori, Giovanni, The theory of democracy revisited, Chatam House Publications, New Jersey, 1987.

-Schwarts, Roberto, "Las ideas fuera de lugar", Estudios Cebrap, núm. 3, 1973.

-Vachet, André, La ideología liberal, Fundamento, Madrid, 1972, 2 vols.

-Villegas, Abelardo, Reforma y revolución en el pensamiento latinoamericano, Siglo XXI, Editores, México, 1979.

- Villoro, Luis, El proceso ideológico de la revolución de independencia, UNAM, México, 1984.

-Viotti da Costa, Emilia, "Liberalism: theory and practice", The brazilian empire, myths and bistories, Chicago University Press, Chicago, 1985.

-Zea, Leopoldo, El positivismo mexicano, FCE, México, 1971. 


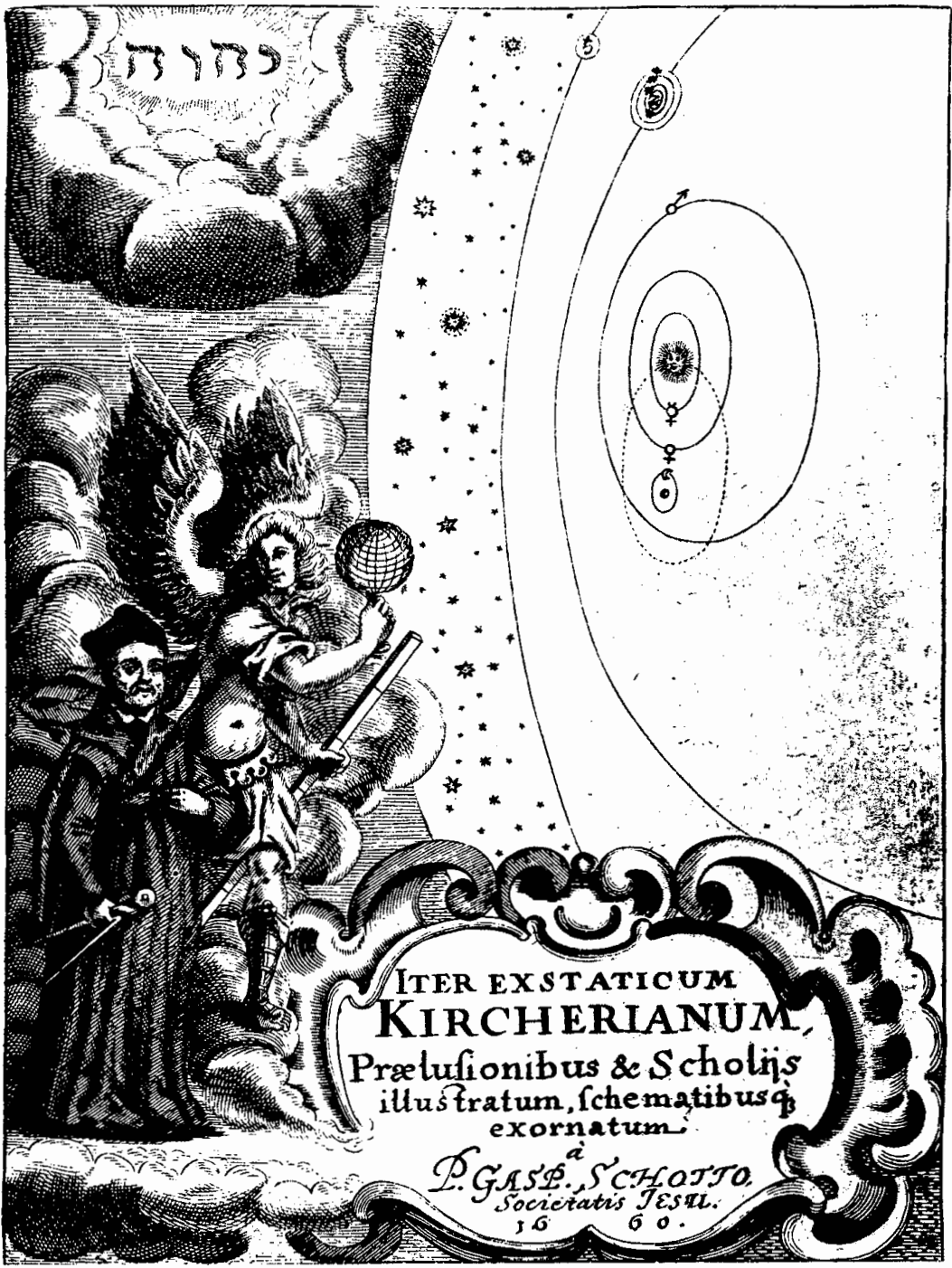

